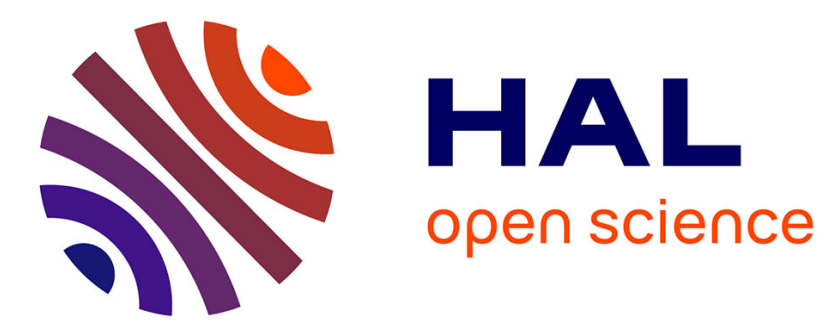

\title{
Geophysically consistent values of the perovskite to post-perovskite transition Clapeyron slope
}

\author{
J W Hernlund, S Labrosse
}

\section{To cite this version:}

J W Hernlund, S Labrosse. Geophysically consistent values of the perovskite to postperovskite transition Clapeyron slope. Geophysical Research Letters, 2007, 34 (5), pp.L05309. 10.1029/2006GL028961 . insu-01387517

\section{HAL Id: insu-01387517 https://hal-insu.archives-ouvertes.fr/insu-01387517}

Submitted on 25 Oct 2016

HAL is a multi-disciplinary open access archive for the deposit and dissemination of scientific research documents, whether they are published or not. The documents may come from teaching and research institutions in France or abroad, or from public or private research centers.
L'archive ouverte pluridisciplinaire HAL, est destinée au dépôt et à la diffusion de documents scientifiques de niveau recherche, publiés ou non, émanant des établissements d'enseignement et de recherche français ou étrangers, des laboratoires publics ou privés. 


\title{
Geophysically consistent values of the perovskite to post-perovskite transition Clapeyron slope
}

\author{
J. W. Hernlund ${ }^{1}$ and S. Labrosse ${ }^{2}$ \\ Received 30 November 2006; revised 4 February 2007; accepted 13 February 2007; published 15 March 2007.
}

[1] The double-crossing hypothesis posits that postperovskite bearing rock in Earth's $\mathrm{D}^{\prime \prime}$ layer exists as a layer above the core-mantle boundary bounded above and below by intersections between a curved thermal boundary layer geotherm and a relatively steep phase boundary. Increasing seismic evidence for the existence of pairs of discontinuities predicted to occur at the top and bottom of this layer motivates an examination of the consistency of this model with mineral physics constraints for the Clapeyron slope of this phase transition. Using independent constraints for a lower bound on temperature in Earth's deep mantle and the temperature of Earth's inner core boundary, we show that a post-perovskite double-crossing is inconsistent with plausible core temperatures for a Clapeyron slope less than about $7 \mathrm{MPa} / \mathrm{K}$, with the higher range of experimental values yielding better agreement with recent estimates of the melting temperature of Earth's core. Citation: Hernlund, J. W. and S. Labrosse (2007), Geophysically consistent values of the perovskite to post-perovskite transition Clapeyron slope, Geophys. Res. Lett., 34, L05309, doi:10.1029/2006GL028961.

\section{Introduction}

[2] The experimentally and theoretically predicted occurrence of post-perovskite(pPv)-bearing rock in Earth's lowermost mantle [Murakami et al., 2004; Oganov and Ono, 2004; Tsuchiya et al., 2004] has been invoked to explain the presence of discontinuous increases in seismic velocity observed in some regions atop the $\mathrm{D}^{\prime \prime}$ layer [Lay and Helmberger, 1983; Wysession et al., 1998]. A deeper rapid seismic velocity decrease has also been proposed beneath the Cocos region [Thomas et al., 2004a] and Eurasia [Thomas et al., 2004b] underneath the velocity increase, and while the detectability of this deeper feature has been questioned [Flores and Lay, 2005] or can be interpreted differently in some regions [Hutko et al., 2006], recent analysis supports the presence of this feature beneath Cocos [Sun et al., 2006] and the mid-Pacific [Lay et al., 2006]. The existence of such discontinuity pairs is predicted by the "double-crossing" hypothesis [Hernlund et al., 2005], in which a layer of pPv-bearing rock appears above the coremantle boundary (CMB), with the upper and lower interfaces identified with intersections of the $\mathrm{D}^{\prime \prime}$ boundary layer geotherm and the perovskite $(\mathrm{Pv})-\mathrm{pPv}$ phase boundary at two different depths (Figure 1).

\footnotetext{
${ }^{1}$ Institut de Physique du Globe de Paris, France.

${ }^{2}$ Laboratoire des Sciences de la Terre, École Normale Supérieure de Lyon, France.

Copyright 2007 by the American Geophysical Union. 0094-8276/07/2006GL028961
}

[3] More importantly, the double-crossing hypothesis offers a simple way to explain why some regions exhibit no detectable discontinuities at all [Wysession et al., 1998] as the consequence of a geotherm that doesn't pass into the $\mathrm{pPv}$ stability field. If the latter effect occurs, $\mathrm{pPv}$ should be present in lens-like structures that laterally pinch out and disappear, which is precisely what is observed in a new high density reflectivity survey of the mid-Pacific [Lay et al., 2006]. On the other hand, if the pPv phase boundary temperature were greater than the $\mathrm{CMB}$ temperature, $\mathrm{pPv}$ would exist as a globally present layer because the CMB is essentially isobaric and isothermal. This alternative scenario is termed the "single-crossing" because the geotherm can only pass through the $\mathrm{pPv}$ phase boundary once, rather than twice, and in this case some other mechanism would be required to hide the ubiquitous $\mathrm{pPv}$ layer from seismic detection where a discontinuity is not observed.

[4] If correct, the double-crossing model also provides a means for mapping temperature at two different depths based upon observed seismic discontinuities. Furthermore, the model gives bounds on core-mantle heat flux since it requires that the temperature of the core-mantle boundary be greater than the $\mathrm{Pv}-\mathrm{pPv}$ phase boundary temperature at $\mathrm{CMB}$ pressure $(\approx 136 \mathrm{GPa})$. While chemical influences upon the phase boundary are probably necessary to explain the presence of $\mathrm{pPv}$ lenses in tomographically fast and slow regions of $\mathrm{D}^{\prime \prime}$ [Wysession et al., 1998; Lay et al., 2006], the relative temperature requirement at the $\mathrm{CMB}$ must always hold true in order to produce these kinds of structures in any setting. Here we leverage this constraint, which would not be possible in a single-crossing scenario, against geophysically consistent estimates for the temperature of the deep mantle and inner core boundary (ICB) to define a plausible range of Clapeyron slopes for the post-perovskite phase transition, $\Gamma_{p P v}$, in a way that is independent of the absolute temperature of the phase boundary, the latter of which is subject to large uncertainties. We find that values higher than about $7 \mathrm{MPa} / \mathrm{K}$ are required for the double-crossing model to be consistent with even the most conservative upper bounds on the temperature at the inner core boundary, bisecting the range of experimental uncertainty for $\Gamma_{p P v}$ that lies between $4 \mathrm{MPa} / \mathrm{K}$ and $13 \mathrm{MPa} / \mathrm{K}$ [Hirose et al., 2006]. A consistent extrapolation of the geotherm is obtained for the value $\Gamma_{p P v}=11.5 \pm$ $1.4 \mathrm{MPa} / \mathrm{K}$ obtained by using a $\mathrm{MgO}$ pressure standard in laser-heated diamond anvil cell (LHDAC) experiments, in agreement with some ab initio values as well as recent estimates for the temperature of the ICB.

\section{Basic Temperature Bounds}

[5] The procedures and uncertainties involved in estimating temperatures in the deep Earth are reviewed by Williams 


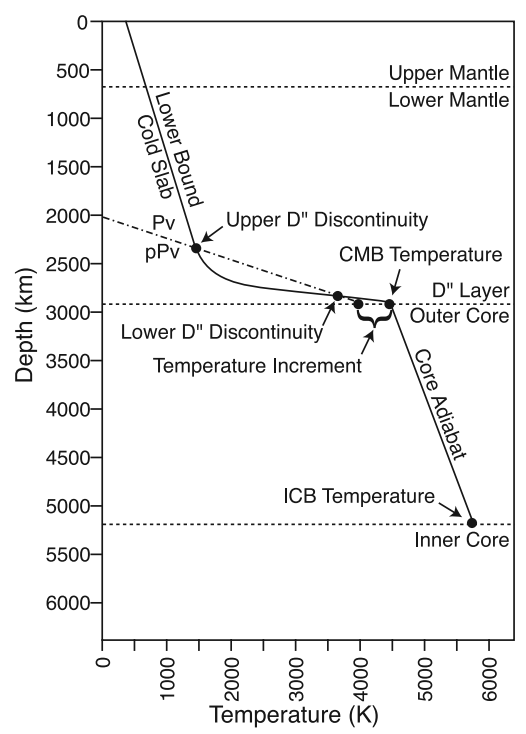

Figure 1. Schematic illustration of a double-crossing geotherm (solid line), which intercepts the $\mathrm{pPv}$ phase boundary (dot-dashed line) at two different depths (indicated as upper and lower $\mathrm{D}^{\prime \prime}$ discontinuities). The particular temperature profile we will be interested in using here is the lowest possible temperature, which is that due to a rapidly subducted slab.

[1998]. We begin with the basic fact that the smallest possible temperature that can be attained in the $\mathrm{D}^{\prime \prime}$ layer would be that due to rapidly (i.e., velocity of order $10 \mathrm{~cm} / \mathrm{yr}$ ) subducted slabs of lithosphere. Increases in the temperature of the slab upon descent would arise due to adiabatic compression $\Delta T_{a d}$, plus heat exchange by conduction with the surrounding mantle, $\Delta T_{\text {cond }}$. An analytical solution for $\Delta T_{\text {cond }}$ in this scenario is given by Davies [1999], for which vertically subducted lithosphere $100 \mathrm{~km}$ thick having an initial potential temperature contrast of $1225 \mathrm{~K}$ with the surrounding ambient mantle and a thermal diffusivity of $10^{-6} \mathrm{~m}^{2} / \mathrm{sec}$ yields a temperature anomaly of about $\Delta T_{\text {slab }} \approx$ $700 \mathrm{~K}$ at $\mathrm{D}^{\prime \prime}$ depths. $\Delta T_{a d}$ depends upon the Grüneisen parameter, which is estimated to be in the range 1.3-2.0 for the lower mantle, yielding a range of around $2400-2800 \mathrm{~K}$ at $\mathrm{D}^{\prime \prime}$ depths for a mantle potential temperature extended from a fixed point at $410 \mathrm{~km}$ depth [Williams, 1998]. Because the adiabatic gradient is proportional to temperature, a cold slab will exhibit a smaller $\Delta T_{a d}$ than ambient mantle by as much as $200 \mathrm{~K}$, and after subtracting $\Delta T_{\text {slab }}=$ $700 \mathrm{~K}$ we obtain a lower bound of $T_{\min }=1500-1900 \mathrm{~K}$ for temperatures in the $\mathrm{D}^{\prime \prime}$ layer. While heat absorption by any endothermic phase transitions (e.g., post-spinel transition at $660 \mathrm{~km}$ depth) could cool a descending slab slightly, this effect is offset by exothermic phase transitions (e.g., the olivine $\rightarrow$ spinel transition at $410 \mathrm{~km}$ depth), and probably small in comparison with other potential effects such as internal heating by decay of radioactive species [e.g., Labrosse, 2002], viscous dissipation accompanying any deformation of the slab [e.g., Conrad and Hager, 2001], slowing of the slab's descent by an increased lower mantle viscosity with depth [e.g., Yamazaki and Karato, 2001], or changes in thermal conductivity at higher temperatures [Badro et al., 2004].
[6] The coldest temperatures in $\mathrm{D}^{\prime \prime}$ should lead to shallow occurrences of any discontinuities associated with the $\mathrm{Pv}-\mathrm{pPv}$ phase transition as a consequence of its positive Clapeyron slope. The upper discontinuity is typically estimated to shallow to around $300 \mathrm{~km}$ (for a review, see Wysession et al. [1998]), and possibly as much $400 \mathrm{~km}$ above the CMB [e.g., Kendall and Shearer, 1994]. Unfortunately, the shallowest values have not yet been corroborated by other studies, and all estimates are nevertheless subject to errors arising from dependence upon the employed reference seismic velocity profile, extensive data processing, and the possibility of extra complexity in mantle structure. Thus we consider the value of the shallowest displacement of the upper $\mathrm{D}^{\prime \prime}$ discontinuity, $h_{\min }$, to be an uncertain parameter. Given $h_{\min }$ we could follow the postperovskite phase boundary to $\mathrm{CMB}$ pressure using $T_{\min }+$ $\rho g h_{\min } / \Gamma_{p P v}$, where $\rho\left(\approx 5500 \mathrm{~kg} / \mathrm{m}^{3}\right)$ is the density, and $g\left(\approx 10 \mathrm{~m} / \mathrm{s}^{2}\right)$ is the gravitational acceleration, yielding a lower bound for $\mathrm{CMB}$ temperature in the range 2800 $6300 \mathrm{~K}$ (see Figure 1) using $h_{\min }=300-400 \mathrm{~km}$. For a constant Grüneisen parameter $\gamma$, the temperature at the ICB and CMB are adiabatically linked by $T_{i c b}=T_{c m b}\left(\rho_{i c b} / \rho_{c m b}\right)^{\gamma}$, with $\rho_{i c b}$ and $\rho_{c m b}$ the density of the outer core just above the ICB and below the CMB respectively. In a review of recent ab initio models, Vočadlo et al. [2003] have derived a remarkably constant adiabatic value of $\gamma \approx 1.51 \pm 0.01$, with the usual density dependence being balanced by an additional temperature dependence. The ratio $\rho_{i c b} / \rho_{c m b}$ can be obtained from PREM [Dziewonski and Anderson, 1981], from which we obtain $T_{i c b}=1.36 T_{c m b}$, or $T_{i c b}=3900-$ $8600 \mathrm{~K}$. Note that this lower bound is not biased, since discontinuities arising from material warmer than the coldest scenario estimated above would give rise to even higher estimates for ICB temperature.

[7] The melting temperature of iron at ICB pressure provides a completely independent constraint upon plausible temperatures in the deep Earth. Most experimental estimates for the melting temperature of pure $\mathrm{Fe}$, when extrapolated to ICB pressure, fall in the range $5600-6500 \mathrm{~K}$ [Anderson and Duba, 1997], while $5980 \pm 70 \mathrm{~K}$ is obtained from thermal physics estimates [Anderson et al., 2003], $6160 \pm 250 \mathrm{~K}$ from a dislocation theory of melting [Poirier, 1986; Poirier and Shankland, 1993], and $6350 \pm 300 \mathrm{~K}$ from recent ab initio calculations [Alfè et al., 2004]. To the melting temperature of pure iron, we must also subtract a depression due to the presence of light alloying elements, which is estimated to be $700 \pm 100 \mathrm{~K}$ from ab initio calculations for compositions agreeing with seismic properties of the inner and outer core [Alfè et al., 2002]. The combined ab initio results yield a $T_{i c b}$ around $5600 \mathrm{~K}$, in close agreement with the value of $5700 \mathrm{~K}$ using elasticity constraints for the inner core [Steinle-Neumann et al., 2001]. It is worth noting that even a very conservative upper bound of $T_{i c b}<6500 \mathrm{~K}$ [Williams, 1998] already falls in the middle of the range of the lower bound of 4000-9400 K required of the double-crossing model. Therefore, a range of independent constraints are mutually inconsistent with one another when linked together by the double-crossing model, even accounting for the large range of uncertainties.

[8] It is useful to isolate, as much as possible, the contribution of $\Gamma_{p P v}$ to the lower bound for $T_{i c b}$. We plot the trade-offs between $\Gamma_{p P v}, h_{\min }$, and $T_{i c b}$ in Figure 2. If we 


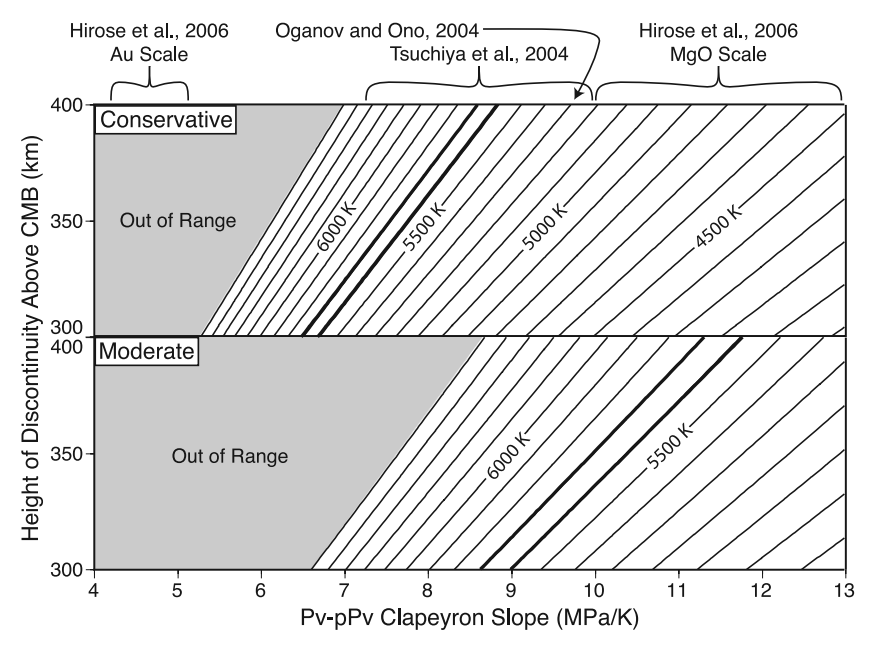

Figure 2. Lower bound of the temperature at the inner core boundary implied by the double-crossing model as a function of the $\mathrm{pPv}$ Clapeyron slope $\Gamma_{p P v}$ and the shallowest displacement of the upper $\mathrm{D}^{\prime \prime}$ discontinuity above the $\mathrm{CMB}$, $h_{\text {min. }}$ (top) The most conservative lower bound for the ICB temperature as discussed in the text, given by $1.36(1500+$ $\left.\rho g h_{\min } / \Gamma_{p P v}\right) \mathrm{K}$. (bottom) A more moderate estimate, using $1.36\left(1800+400+\rho g h_{\min } / \Gamma_{p P v}\right) \mathrm{K}$, where the extra $400 \mathrm{~K}$ is an arbitrary estimate of the temperature increment between the $\mathrm{CMB}$ and the $\mathrm{pPv}$ phase boundary temperature in Figure 1. Various experimental and ab initio constraints are indicated at the top of Figure 2. The bold contours indicate recent ICB temperature estimates of $5600 \mathrm{~K}$ [Alfè et al., 2002] and $5700 \mathrm{~K}$ [Steinle-Neumann et al., 2001], while the light grey region indicates values that are too extreme to be supported by any estimates.

apply the most conservative bounds discussed above, it is clear that $\Gamma_{p P v}$ less than about $6-7 \mathrm{MPa} / \mathrm{K}$ implies ICB temperatures that are unreasonably high. We note that the predicted lower bound for $T_{i c b}$ would be higher if we chose a larger mantle adiabatic gradient, smaller temperature anomaly due to the slab, or non-zero temperature increment between the $\mathrm{CMB}$ and the $\mathrm{pPv}$ phase boundary at $\mathrm{CMB}$ pressure. We also plot the lower bound for $T_{i c b}$ using a temperature increment of $400 \mathrm{~K}$ and average mantle adiabatic gradient $0.375 \mathrm{~K} / \mathrm{km}$, the latter of which is similar to the ab initio value preferred by Ono and Oganov [2005]. Various estimates of the $\mathrm{Pv}-\mathrm{pPv}$ Clapeyron slope are also given (for a recent review see Hirose [2006]). It is interesting that the upper limit on $T_{i c b}$ bisects the range of experimental uncertainty in $\Gamma_{p P v}$ induced by the various pressure standards used in LHDAC experiments [Hirose et al., 2006]. The smallest $\Gamma_{p P v}$ of about $4.7 \pm 0.5 \mathrm{MPa} / \mathrm{K}$ was obtained using an Au pressure standard [Tsuchiya, 2003], while an MgO pressure standard [Speziale et al., 2001] in the same experiments yields $\Gamma_{p P v}=11.5 \pm 0.4 \mathrm{MPa} / \mathrm{K}$. Therefore, if this particular Au pressure standard is correct, then the possibility for a double-crossing appears to be incompatible with plausible core temperatures.

\section{Discussion and Conclusion}

[9] Hirose et al. [2006] argue that the Speziale et al. [2001] $\mathrm{MgO}$ standard, which also yields better agreement with experiments conducted using a Pt standard, is probably the best choice for geophysical applications. The $\mathrm{MgO}$ pressure standard is also recommended by $\mathrm{Fei}$ et al. [2004] since it yields the best agreement with the postspinel phase boundary for plausible temperatures at depths of the $660 \mathrm{~km}$ seismic discontinuity. Thus we could also argue here that consistency of the experimentally determined values of the Clapeyron slope with plausible models for the occurrence of post-perovskite in Earth's D" layer also supports the geophysical consistency of the $\mathrm{MgO}$ pressure standard. However, the strength of such an argument by itself is not as convincing in this setting, since the experimental and seismic data bearing upon the question at hand is significantly less certain than data regarding the much shallower $660 \mathrm{~km}$ seismic discontinuity.

[10] Any future study that incorporates a $\mathrm{pPv}$ doublecrossing should consider the kinds of trade-offs described above. In particular, where a range of parameters is to be explored, values of the Clapeyron slope less than about $8 \mathrm{MPa} / \mathrm{K}$ should not be considered appropriate, and larger values should be implemented if a lower range of temperature estimates for the core is assumed [e.g., Boehler, 1993]. The finding that only the higher range of Clapeyron slopes yields reasonable temperatures in the deep Earth also carries implications for the heat flow implied by the doublecrossing model, favoring the lower range of values given in previous studies [Hernlund et al., 2005; Lay et al., 2006]. However, when comparing these constraints it is also important to consider the possibility that $\mathrm{Pv}-\mathrm{pPv}$ transitions in chemically distinct regions may exhibit different effective Clapeyron slopes [e.g., Spera et al., 2006].

[11] An important alternative view can also be stated in the form of yet another hypothesis test for the doublecrossing model. In particular, if the Clapeyron Slope for the $\mathrm{pPv}$ transition can be shown to actually be smaller than those implying reasonable values for the temperature of the ICB, then the hypothesis can be falsified. In principle, this kind of falsification is rather simple, and can be done entirely within the confines of a high pressure laboratory. However, better seismic estimates of the shallowest displacement of the phase boundary in cool (and presumably fast) regions of $\mathrm{D}^{\prime \prime}$ could provide more leverage if shallower displacements of the upper discontinuity can be more confidently established.

[12] Acknowledgments. We thank Orson Anderson, Edward Garnero, Abby Kavner, Thorne Lay, William B. Moore, Paul H. Roberts, Gerald Schubert, David Stevenson, and Paul Tackley for productive discussions. Reviews by Allen McNamara and Christine Reif helped to improve the clarity of the presentation. This work is supported by the French Ministry of Research and the INSU DyETI program.

\section{References}

Alfè, D., M. J. Gillan, and G. D. Price (2002), Composition and temperature of the Earth's core constrained by combining ab initio calculations and seismic data, Earth Planet. Sci. Lett., 195, 91-98.

Alfè, D., G. D. Price, and M. J. Gillan (2004), The melting curve of iron from quantum mechanics calculations, J. Phys. Chem. Solids, 65, 15731580, doi:10.1016/j.jpcs.2003.12.014.

Anderson, O. L., and A. Duba (1997), Experimental melting curve of iron revisited, J. Geophys. Res., 102, 22,659-22,669.

Anderson, O. L., D. G. Isaak, and V. E. Nelson (2003), The high-pressure melting temperature of hexagonal close-packed iron determined from thermal physics, J. Phys. Chem. Solids, 64, 2125-2131.

Badro, J., J.-P. Rueff, G. Vankó, G. Monaco, G. Fiquet, and F. Guyot (2004), Electronic transitions in perovskite: Possible nonconvecting layers in the lower mantle, Science, 305, 383-386. 
Boehler, R. (1993), Temperatures in the Earth's core from melting-point measurements of iron at high static pressures, Nature, 363, 534-536, doi:10.1038/363534a0.

Conrad, C. P., and B. H. Hager (2001), Mantle convection with strong subduction zones, Geophys. J. Int., 144, 271-288

Davies, J. H. (1999), Simple analytic model for subduction zone thermal structure, Geophys. J. Int., 139, 823-828.

Dziewonski, A. M., and D. L. Anderson (1981), Preliminary reference Earth model, Phys. Earth Planet. Inter., 25, 297-356.

Fei, Y., J. Van Orman, J. Li, W. van Westrenen, C. Sanloup, W. Minarik, K. Hirose, T. Komabayashi, M. Walter, and K. Funakoshi (2004), Experimentally determined postspinel transformation boundary in $\mathrm{Mg}_{2} \mathrm{SiO}_{4}$ using $\mathrm{MgO}$ as an internal pressure standard and its geophysical implications, J. Geophys. Res., 109, B02305, doi:10.1029/2003JB002562.

Flores, C., and T. Lay (2005), The trouble with seeing double, Geophys. Res. Lett., 32, L24305, doi:10.1029/2005GL024366.

Hernlund, J. W., C. Thomas, and P. J. Tackley (2005), A doubling of the post-perovskite phase boundary and structure of the Earth's lowermost mantle, Nature, 434, 882-886, doi:10.1038/nature03472.

Hirose, K. (2006), Postperovskite phase transition and its geophysical implications, Rev. Geophys., 44, RG3001, doi:10.1029/2005RG000186.

Hirose, K., R. Sinmyo, N. Sata, and Y. Ohishi (2006), Determination of post-perovskite phase transition boundary in $\mathrm{MgSiO}_{3}$ using $\mathrm{Au}$ and $\mathrm{MgO}$ pressure standards, Geophys. Res. Lett., 33, L01310, doi:10.1029/ 2005 GL024468.

Hutko, A., T. Lay, E. J. Garnero, and J. S. Revenaugh (2006), Seismic detection of folded, subducted lithosphere at the core-mantle boundary, Nature, 441, 333-336.

Kendall, J.-M., and P. M. Shearer (1994), Lateral variations in $\mathrm{D}^{\prime \prime}$ thickness from long-period shear wave data, J. Geophys. Res., 99, 11,575-11,590.

Labrosse, S. (2002), Hotspots, mantle plumes and core heat loss, Earth Planet. Sci. Lett., 199, 147-156.

Lay, T., and D. V. Helmberger (1983), A shear velocity discontinuity in the lower mantle, Geophys. Res. Lett., 10, 63-66.

Lay, T., J. Hernlund, E. J. Garnero, and M. S. Thorne (2006), A postperovskite lens and $\mathrm{D}^{\prime \prime}$ heat flux beneath the central Pacific, Science, 314, 1272-1276, doi:10.1126/science. 1133280 .

Murakami, M., K. Hirose, N. Sata, Y. Ohishi, and K. Kawamura (2004), Phase transition of $\mathrm{MgSiO}_{3}$ perovskite in the deep lower mantle, Science, 304, 855-858.

Oganov, A. R., and S. Ono (2004), Theoretical and experimental evidence for a post-perovskite phase of $\mathrm{MgSiO}_{3}$ in Earth's D" layer, Nature, 430, $445-448$

Ono, S., and A. R. Oganov (2005), In situ observations of phase transition between perovskite and $\mathrm{CaIrO}_{3}$-type phase in $\mathrm{MgSiO}_{3}$ and pyrolitic mantle composition, Earth Planet. Sci. Lett., 236, 914-932.

Poirier, J.-P. (1986), Dislocation-mediated melting of iron and the temperature of the Earth's core, Geophys. J. R. Astron. Soc., 85, 315-328.
Poirier, J.-P., and T. J. Shankland (1993), Dislocation melting of iron and temperature of the inner core boundary, revisited, Geophys. J. Int., 115, $147-151$.

Spera, F. J., D. A. Yuen, and G. Giles (2006), Tradeoffs in chemical and thermal variations in the post-perovskite phase transition: Mixed phase regions in the deep lower mantle?, Phys. Earth Planet. Inter., 159, 234246, doi:10.1016/j.pepi.2006.07.007.

Speziale, S., C. Zha, T. S. Duffy, R. J. Hemley, and H. K. Mao (2001), Quasi-hydrostatic compression of magnesium oxide to $52 \mathrm{GPa}$ : Implications for the pressure-volume-temperature equation of state, J. Geophys. Res., 106, 515-528.

Steinle-Neumann, G., L. Stixrude, R. E. Cohen, and O. Gülseren (2001), Elasticity of iron at the temperature of the Earth's inner core, Nature, 413, 57-60, doi:10.1038/35092536.

Sun, D., T.-R. A. Song, and D. Helmberger (2006), Complexity of D" in the presence of slab-debris and phase changes, Geophys. Res. Lett., 33, L12S07, doi:10.1029/2005GL025384.

Thomas, C., E. J. Garnero, and T. Lay (2004a), High-resolution imaging of lowermost mantle structure under the Cocos plate, J. Geophys. Res., 109, B08307, doi:10.1029/2004JB003013.

Thomas, C., J. Kendall, and J. Lowman (2004b), Lower-mantle seismic discontinuities and the thermal morphology of subducted slabs, Earth Planet. Sci. Lett., 225, 105-113.

Tsuchiya, T. (2003), First-principles prediction of the $P-V-T$ equation of state of gold and the 660-km discontinuity in Earth's mantle, J. Geophys. Res., 108(B10), 2462, doi:10.1029/2003JB002446.

Tsuchiya, T., J. Tsuchiya, K. Umemoto, and R. M. Wentzcovitch (2004), Phase transition in $\mathrm{MgSiO}_{3}$ perovskite in the Earth's lower mantle, Earth Planet. Sci. Lett., 224, 241-248.

Vočadlo, L., D. Alfè, M. J. Gillan, and G. D. Price (2003), The properties of iron under core conditions from first principles calculations, Phys. Earth Planet. Inter., 140, 101-125.

Williams, Q. (1998), The temperature contrast across $\mathrm{D}^{\prime \prime}$, in The CoreMantle Boundary Region, Geodyn. Ser., vol. 28, edited by M. Gurnis et al., pp. 73-81, AGU, Washington, D. C.

Wysession, M. E., T. Lay, J. Revenaugh, Q. Williams, E. J. Garnero, R. Jeanloz, and L. H. Kellogg (1998), The $\mathrm{D}^{\prime \prime}$ discontinuity and its implications, in The Core-Mantle Boundary Region, Geodyn. Ser., vol. 28, edited by M. Gurnis et al., pp. 273-297, AGU, Washington, D. C. Yamazaki, D., and S. Karato (2001), Some mineral physics constraints on rheology of Earth's lower mantle, Am. Mineral., 86, 385-391.

J. W. Hernlund, Institut de Physique du Globe de Paris, 4 Place Jussieu, F-75252 Paris Cedex 05, France. (hernlund@ipgp.jussieu.fr)

S. Labrosse, Laboratoire des Sciences de la Terre, Ecole Normale Supérieure de Lyon, 46 Allée d'Italie, F-69364 Lyon Cedex 07, France. (stephane.labrosse@ens-lyon.fr) 